\title{
Toward a pragmatic account and taxonomy of valuative speech acts
}

\author{
Ernesto Wong García \\ University of Havana
}

This paper presents an account of value ascription as an illocutionary force, based on four claims: (1) that value ascription is a kind of illocutionary force, defining a specific kind of speech act, i.e. valuative speech acts (VSAs); (2) that the point of VSAs is ascribing an axiological value to a referent; (3) that VSAs create a weak, inside-oriented truth commitment; and (4) that they are therefore more about the valuating subject than they are about the valuated object. This illocutionary force is described using criteria taken from contemporary speech act theory as well as others that have proven informative. This description results in a rich taxonomy of VSAs. This shows the viability and fruitfulness of a pragmatic account of value ascription, and it contributes to the development of speech act theory, specifically with regard to the distinction between primary and secondary illocutionary points, and the speech act taxonomy itself.

Keywords: value ascription, valuative speech act, appraisal, evaluation, illocutionary force, speech act theory, pragmatics

\section{Introduction}

The issue of value ascription has been widely discussed in both philosophy and linguistics, particularly in the fields of semantics and pragmatics. It is generally agreed that an utterance like $X$ is good / bad / beautiful / useless / smart is valuative ${ }^{1}$ insofar as its speaker thereby ascribes a positive or negative value to a referent $X$.

Within contemporary linguistics, two main research programs aim to describe and account for valuative meaning. One is found within Systemic Functional Linguistics (SFL), and is known as the appraisal framework, developed

1. I use the general term valuative, instead of the more common evaluative, because the latter will be used here to refer to a sub-kind of valuative speech acts, namely status-based, institutional valuative speech acts (cf. Section 3.3.1). 
mainly by Martin and White (2005). The other is the theory of semantic modality, developed mainly by Caballero Díaz (2014) and Galbán Pozo (1999, 2003). Martin and White (2005,38-40) offer a historical perspective on evaluative language analysis, and Oteíza (2017) presents a survey of the appraisal framework, and of recent developments in English and other languages.

Within the appraisal framework, appraisal is seen as "an interpersonal system at the level of discourse semantics" (Martin and White 2005,33), with three subsystems: attitude, engagement, and graduation. This paper aims to show that, in addition to being a discourse-semantic object, value ascription can also be described as a pragmatic object, namely, as an illocutionary force, and to propose a taxonomy of speech acts defined by said illocutionary force. This idea is also found in Caballero Díaz's (2014) theory of semantic modality, although the specific question of characterizing the valuative illocutionary force in terms of contemporary speech act theory has never been addressed.

I will be relying mainly on a Searlean version of speech act theory, because it provides a framework for a point-by-point characterization like the one I will present. However, Oishi has remarked, with some reason, that post-Austinian theorists like Searle "have wittingly or unwittingly reduced [illocutionary acts] to something else, specifically, intentions" $(2006,5)$. I will indeed be focusing on intention, but, without attempting a reconciliation between approaches, I will nevertheless make use of some elements from the Austinian account of speech acts, as developed by Sbisà $(2007,2014)$ and by Austin $(1962)$ himself.

Section 2 expounds and defends the four main theoretical claims of this paper, and Section 3 offers a characterization of the valuative illocutionary force based on illocutionary criteria, which provide the basis for a typology of valuative speech acts (VSAs). By way of a conclusion, Section 4 considers how this account of value ascription fits in contemporary speech act theory, and outlines further issues to be tackled.

\section{What is valuating?}

The theory of semantic modality (Caballero Díaz 2014; Galbán Pozo 1999, 2003), a subjectivistic semantic theory that aims to describe the expression of speaker subjectivity in language and discourse, rests upon two main tenets concerning value ascription: (1) value ascription corresponds to a specific kind of speech act, namely, VSAs, defined by their valuative illocutionary force; and (2) value ascription, being a kind of semantic modality, consists in the expression of a certain kind of subjective stance toward something. This second tenet is also found in Martin and White's appraisal framework, where a notion similar to 
'semantic modality' (understood broadly as the expression of speaker subjectivity) surfaces in the form of such concepts as 'affect', 'modality', 'intensification', 'vague language' $(2005,2)$. Note that the notion of 'semantic modality' expands on the traditional concept of 'modality' used in logic and linguistics, where it is tied to a proposition's truth conditions.

For the specific case of value ascription, this subjective stance takes the form of axiological values ascribed to the referent being talked about. The two contrary extremes are GOOD (the positive value) and BAD (the negative value). By means of a semiotic square in the spirit of Greimas (1966), an opposition between contradictory values is established: NOT BAD and NOT GOOD. The conjunction of this pair creates the complex notion NEITHER GOOD NOR BAD (the ambiguous value). If we place these values along an axis, they form an axiological scale:

BAD $\leftarrow$ NOT GOOD $\leftarrow$ NEITHER GOOD NOR BAD $\rightarrow$ NOT BAD $\rightarrow$ GOOD

It is also possible to combine the two extreme values, GOOD and BAD, to create the complex notion вотн GOOD AND BAD (the ambivalent value).

These are all general semantic notions, the precise meaning of which varies according to the semantic domain in which the referent is valuated. Thus, GOOD and BAD can become 'beautiful' and 'ugly' in the aesthetic domain; 'smart' and 'dumb' in the intellectual domain; 'useful' and 'useless' in the practical domain; 'fair' and 'unfair' in the moral domain; 'healthy' and 'sick' in the physiological domain, and so on.

Now, although from a psychological-semantic perspective, it is true that value ascription involves expressing a certain subjective stance toward something, from an illocutionary standpoint, this cannot be the defining trait of VSAs. Any speech act expressing an intentional mental state can be said to express a certain subjective stance, but they are not all valuative (notably, belief ascriptions like I believe that $p$ ). In the rest of this section, I will expound and defend the four main theoretical claims of this paper: (1) that value ascription is a kind of illocutionary force, defining a specific kind a speech act, i.e. VSAs; (2) that the point of VSAs is ascribing an axiological value to a referent; (3) that VSAs create a weak, inside-oriented truth commitment; and (4) that they are therefore more about the valuating subject than they are about the valuated object.

\subsection{Value ascription is a kind of illocutionary force}

The claim that value ascription corresponds to a specific kind of speech act may seem problematic. It is challenging, perhaps impossible, to find strictly valuative speech acts: it seems that value ascription is just not an autonomous kind 
of illocutionary force. In other words, value ascription is always found alongside other illocutionary forces, typically assertoric ( $X$ is beautiful), expressive (What a great X!), and declarative (We find the defendant guilty). From an illocutionary-logical standpoint (Searle and Vanderveken 1985; Green 2017), then, it would appear that performing a VSA always commits us to performing some other kind of speech act.

However, some speech acts are unquestionably valuative. In utterances like $X$ is good / bad / beautiful, etc., it is patent that the speaker is doing something with the referent beyond - and rather than - merely asserting something about it. For the time being, let's say that that something is expressing a subjective stance toward it. So we would like to still be able to say that value ascription involves performing a specific kind of speech act, a position coherent with the Austinian framework, where "values are the effect of choices and preferences and therefore belong with illocutionary force" and "value judgments are actions" (Sbisà 2014, 626), as well as with the SFL appraisal framework, which takes the expression of an attitude to be not "simply a personal matter [...] but a truly interpersonal matter, in that the basic reason for advancing an opinion is to elicit a response of solidarity from the addressee" (Martin, quoted in Oteíza $(2017,457)$ ). This possibility is salvaged by distinguishing, as Siebel (2002) does - following Ulkan (1992) - , between primary and secondary illocutionary points (PIP and SIP).

A similar distinction had been put forward by Searle (1975), in his account of indirect speech acts, between primary and secondary illocutionary acts (PIA and SIA). To him, the PIA corresponds to the indirect act (the one not performed literally), whereas the SIA corresponds to the direct act (the one performed in the literal utterance of a sentence). This is, however, not how I will understand the distinction above. Searle's distinction is meant to account for the speaker's use of mutually shared background information (together with the hearer's rationality and inference powers) to communicate more than she actually says, as in uttering It's hot in here as a request to open a window.

I will instead rely on Siebel's distinction. In his words, the PIP is "the intention on which the other intentions depend insofar as their realization is conceived as a means to achieve the primary intention's goal" $(2002,135)$. I see here a slight but relevant difference: I take Searle's distinction, which is based on a relationship between illocutionary acts, to imply that the indirect act (the PIA) could be performed literally (the speaker could just say Open the window), whereas Siebel's, which is based on a relationship between illocutionary points (IP), implies no such thing.

If we were to follow Searle, a speech act like $X$ is beautiful would have to be analyzed as an assertive (SIA, direct act performed literally) that accomplishes a VSA (PIA, indirect act not performed literally). But if VSAs are in fact not an 
autonomous kind of speech act, this "indirect" VSA could never be performed "literally", that is, without the assertive. In addition, $X$ is beautiful is as direct a VSA as we can find. No such problem arises in saying that VSAs, not having an autonomous kind of IP, rely on other, secondary IPs (assertoric, expressive, declarative) in order to be performed.

\subsection{The point of VSAs}

Above, I provisionally posited that the purpose of VSAs is to express a subjective stance toward something. Now, value subjectivism is far from uncontroversial and I do not have the space to develop an argument. I will be taking what I find to be the most plausible hypothesis, i.e. that any value ascription is subjective. Be that as it may, people are often convinced that they are being objective when ascribing value. They may be wrong, but the important thing here is that, if the IP of a VSA were in fact expressing a subjective stance, these people would be performing a speech act unknowingly.

If we look at other kinds of speech act, we find that it is impossible to give an order without knowing that one is giving an order, to make a request for information without knowing that one is requesting information, to assert something without knowing that one is asserting something, etc. If we additionally acknowledge the existence of institutional VSAs (e.g. a judge's verdict), which are perceived as reflecting objectivity, it seems more appropriate to say that, in these cases, what one does intentionally (and thus knowingly) is ascribe an axiological value to a referent, that is, say that a given object is, in some sense, good, bad, or something in between. I will show (see below, 2.3) that this is not quite the same as asserting something about it.

This leaves room for possible claims of objectivity, because it does not commit us or the speaker to any fundamentally subjective quality of such values (nor to their reality or universality). It also has the advantage of describing VSAs regardless of the secondary IPs to which they happen to be associated: assertoric, expressive, declarative, etc. The speech acts $X$ is beautiful, What a great X!, and We find the defendant guilty, all have in common the fact that an axiological value is ascribed to a referent, i.e. they are all valuative.

The ascription of an axiological value further distinguishes VSAs from expressives like apologizing, thanking, and congratulating, whereby, as defined by Searle, "the speaker expresses his feelings and attitudes about some state of affairs specified by the propositional content" $(2002,5)$. Apart from the fact that leaving these 'attitudes' unspecified invites subsuming propositional attitudes like belief 
ascriptions under expressives, ${ }^{2}$ there is an intuitively obvious difference between expressing how you feel about a given state of affairs and actually saying that it is, in some sense, good or bad. The expression of some positive feelings or 'attitudes' about a state of affairs admittedly implies the ascription of a positive value to said state of affairs, e.g. I'm glad you're here implies that I believe it to be (in some sense) good that you are here. The same can be said of some negative feelings and 'attitudes'. It might even be argued that expressing a feeling or 'attitude' toward something always entails the ascription of an axiological value. But crucially, we can have value ascription without expression of feeling, as in She's a good student or He's very smart.

VSAs, then, have a primary IP that relies on other, secondary IPs as the means of ascribing value. ${ }^{3}$ Thus, although a speech act like $X$ is beautiful seems like an assertive (something seems to be asserted about $\mathrm{X}$ ), this is not its primary IP: the speaker's intent here is not to commit herself to the truth of her statement (like in primarily assertoric speech acts), but rather to ascribe an axiological value to $\mathrm{X}$. The assertion is the means by which she does so. Conversely, a speech act like Take down that hideous painting, although it contains an ascribed value (hideous), cannot be said to be primarily valuative. It aims to cause the hearer to take a particular action, and it is thus a directive speech act. Could the value ascription here be considered a secondary IP, that is, a means to achieve the primary directive one? Or should it best be thought of as merely a valuative presupposition? I choose to leave this question open, as it has no bearing on primarily valuative speech acts.

I would, however, say that this distinction between primary and secondary IPs permits us to readily (and rather intuitively) differentiate, for instance, between assertoric VSAs ( $X$ is beautiful) and valuative assertives (That beautiful $X$ is mine). However, a principled, formal differentiation of this sort must be deferred.

One could argue that, rather than make use of secondary IPs, VSAs co-opt what Searle and Vanderveken (1985) call 'illocutionary force indicating devices' (IFIDs). This would mean, for example, that an assertoric VSA like $X$ is beautiful has co-opted the simple declarative form of the sentence, which is typically an assertoric IFID. However, this overly reduces the problem. The relationship between an assertoric VSA and the assertive that provides its secondary IP is more nuanced.

2. Siebel $(2002,133)$ reaches a similar conclusion, although for slightly different reasons.

3. A similar intuition leads González de Prado Salas and Milić (2018) to analyze aesthetic judgments as double speech acts, constituted by an assertion and a recommendation that the audience come to share the speaker's judgment. Their proposal has substantial merit, not only in this respect, but whether it is relevant to my analysis, and whether it extends to all kinds of value ascription, remains to be determined. 


\subsection{The truth commitment of VSAs}

The main reason why VSAs differ from assertives has to do with the truth commitment that they bring about. A primarily assertoric speech act like $X$ is red commits its speaker to the truth of her statement in a way that, say, $X$ is beautiful does not seem to. If a speaker claims that some object is red, and the hearer believes it to be white, one of them is necessarily wrong. Furthermore, if the speaker's claim turns out to be false, the hearer can accuse her of lying, or simply conclude that she has impaired perception.

This is not the case for $X$ is beautiful. If a speaker claims that a certain object is beautiful, and the hearer believes otherwise, neither is necessarily wrong (or right). Some would even find it problematic to think of a statement like $X$ is beautiful as having a truth value, but this issue lies outside the scope of this paper. ${ }^{4} \mathrm{My}$ point is that, in this case, speaker and hearer can "agree to disagree" - what Kölbel (2003) calls 'faultless disagreement' - , which is impossible in the first scenario: all things being equal, one cannot rationally "agree to disagree" on whether a visible object is red or white.

Truth-commitment thus seems to be weaker for VSAs, like $X$ is beautiful, than it is for primarily assertoric acts, like $X$ is red. One cannot rationally hold someone to the truth of their axiological statements (although they can be held to having such opinions and acting accordingly). ${ }^{5}$ This is probably due to the socially recognized subjective quality of VSAs, not in the sense that they denote observerdependent or observer-relative facts (which they nevertheless do), but in the sense that they are (tacitly) recognized as "coming from the inside" of the speaker, what I will call an inside-oriented truth commitment, in a way that assertives like $X$ is red are not, because their truth-commitment is perceived as relating to "the outside" of the speaker, i.e. to the world, an outside-oriented truth commitment.

This inward orientation of VSAs brings them closer to expressives. However, we already saw a first way in which VSAs differ from expressives: no expression of feeling is needed for value ascription. Let's now look at two additional, non-trivial differences, both of which are, perhaps not surprisingly, truth-related.

A second difference has to do with expressives' direction of fit. Expressives are said to have a null or 'Presup', in Searle (2010), direction of fit, because they

4. One could claim, with Austin (1962) and Sbisà (2014), that value judgments (included among the verdictives) cannot be thought of as being true or false, but rather as being 'correct' or 'incorrect'. However, lacking an explicit account of this 'correctness', I prefer not to approach this from an Austinian standpoint.

5. If we agree with Austin, and include VSAs under verdictives, support for this is found in his claim that verdictives commit us "to those [actions] necessary for consistency with and support of our verdict" $(1962,158)$. 
presuppose the truth of their propositional content. Thus, a primarily expressive act like Thank you for helping me does not assert the truth of you helping me, nor does it enjoin the world to conform to it, nor does it make it so just by being uttered; it merely presupposes that you did in fact help me. VSAs do not appear to work like this. A VSA like $X$ is beautiful cannot be said to presuppose the truth of anything, presumably because there is nothing to presuppose. I nevertheless defer discussing the notion of direction of fit and how it applies to VSAs.

To be sure, this does not exclude the fact that some VSAs, e.g. It's good that you came, do have a propositional content the truth of at least part of which is presupposed. These cases show a third way in which VSAs differ from expressives. For the latter, faultless disagreement is not an option, and one could argue that neither are "faultful" disagreement or just plain agreement. If I utter Thank you for helping me and you reply with I (dis)agree or You're right / wrong, what exactly could you mean? My guess is, very little beyond perhaps confirming or denying that you did in fact help me. ${ }^{6}$ On the contrary, it is perfectly normal, and meaningful, to respond to utterances like $X$ is beautiful or It's good that you came with expressions of agreement or disagreement (cf. 3.5) that do not pertain to some presupposed truth.

The following fragment (1) (McGowan 2018) is an apparent counterexample:

(1) Rose McGowan: In Citizen Rose, my poor sister... She's Canadian, you see...

Stephen Colbert: I'm so sorry.

RM: No, she's so lucky! [...]

Colbert's expressive act of condoling is intended as a joke, but what is relevant here is McGowan's response of overt disagreement. It seems to prove that it is in fact possible to (dis)agree with expressives. However, what McGowan is disagreeing with is not Colbert's expressive act, but rather its implied ascription of a negative value to her sister's condition. This is evident from the fact that her retort is not No, you're not sorry (which would question the sincerity of Colbert's speech act, but still would not disagree with it), but No, she's so lucky, intended to contradict the implication that her sister is unlucky to be Canadian.

6. A possible counterexample is You should(n't) be thanking me, but this is quite different from something like Yes, you're thanking me or No, you're not thanking me. 


\subsection{So what are VSAs about?}

Returning to the issue of truth, then, expressives presuppose the truth of their propositional content, and there are ways to assess the truth of assertives: they are satisfied by their correspondence to states of affairs in the world.

VSAs, on the other hand, are a matter of opinion, and I would suggest that they are all paraphrasable, without any loss of meaning, by a statement of the form ' $\mathrm{X}$ seems $\mathrm{Y}$ to $\mathrm{Z}$ ' (where $\mathrm{X}$ is the valuated referent, $\mathrm{Y}$ is the ascribed axiological value, and $\mathrm{Z}$ is the valuating subject). One would be hard pressed to find a method for assessing the truth of such a statement, because it pertains to a qualitative state existing solely in the mind of the speaker. To put it plainly, VSAs are not claims about the world, but claims about how the speaker sees the world, that is, expressions of speaker subjectivity par excellence.

The difficulty in assessing the truth value of thus-paraphrased VSAs extends to any other statement of the same form, e.g. The store seems closed to me. However, non-valuative "perceptual" statements like this one invariably have a "factual" counterpart, e.g. The store is closed, with different truth conditions. This is not the case for VSAs. A valuative statement like That painting seems beautiful to me and its counterpart That painting is beautiful appear to have identical truth conditions (inside-truth conditions, if they have any): they are semantically synonymous, although there are some pragmatic differences, namely, the strength of the IP (cf. 3.2).

The claim that VSAs bring about an inside-oriented truth commitment, and that they overtly reflect how the speaker sees the world, rather than the way the world is, would explain why someone's VSAs can readily be used to describe them, while assertives are less so: to the question What's Jill like?, we can answer Well, she thinks jazz sucks (Jill's value ascription), and this is understood as providing a characterization of Jill, whereas Well, she says jazz has different subgenres is perceived as irrelevant, at best. ${ }^{7}$

I take this to mean that VSAs, in a non-trivial sense, are about the valuating subject, not about the world, whereas assertives are about the world, not about the asserting subject. This holds even for cases where the speaker non-valuatively asserts something about herself, like I'm 30 years old: unlike valuative statements, there are speaker-independent (or world-based) ways of assessing the truth of this assertion.

7. This is, however, not always so. We can imagine someone asking, 'What's Jill like?' and someone else answering, 'Well, she says the Earth is flat,' an assertion about the world that might nevertheless provide a characterization of Jill. 
To sum up, value ascription is a distinct kind of illocutionary force, albeit not an autonomous one, the IP of which is to ascribe an axiological value to a referent. VSAs rely on secondary IPs (assertoric, expressive, declarative) to be performed. Unlike expressives, VSAs do not necessarily involve the expression of feeling, nor do they necessarily presuppose the truth of their propositional content. Unlike assertives, VSAs create a weak, inside-oriented truth commitment, in the sense that the valuating subject cannot be rationally held to the truth of her valuative statements, because these reflect the way she sees the world, not the way the world is. This also means that VSAs are taken to be about the valuating subject rather than about the valuated object. Unlike both expressives and assertives, VSAs tolerate faultless disagreement.

\section{The valuative illocutionary force}

I have claimed that the IP of VSAs is to ascribe an axiological value to a referent. This distinguishes VSAs from other speech acts, especially assertives. Let us now turn to other criteria, which will characterize the valuative illocutionary force, and provide the basis for a typology of VSAs.

\subsection{Felicity conditions}

As it is problematic to assess the truth of VSAs (assuming that they have truth conditions at all), because they bring about a particular, inside-oriented truth commitment, it seems unfitting to speak of a VSA's conditions of satisfaction.

According to Searle, "intentional states in general are representations of their conditions of satisfaction" $(2010,30)$ and "the key to understanding intentionality is conditions of satisfaction" $(2010,32)$. Both claims, taken together, imply that, for something to be an intentional state, it must have conditions of satisfaction. To say that a valuative stance toward an object is an intentional state is tautological. Still, if this state cannot be satisfied by truth, I do not see at this time what its conditions of satisfaction could be. I will therefore consider instead its felicity conditions, in Austin's (1962) sense, which include Searle's preparatory conditions.

For a VSA to be felicitous, two main conditions have to be met: (1) the particular axiological scale must be appropriate to the valuated referent according to the situation, e.g. at the end of a trial, the defendant is not ascribed values on a scale of A, A-, B+, B, etc., but is found guilty or not guilty; and (2) the valuated object must have properties that can provide a focus for the values of the axiological scale, e.g. a piece of news cannot be ascribed the values skillful or clumsy (dexterity is not one of its properties), but can be described as happy, 
upsetting, comforting, disturbing, according to the effect it has, or, more plainly, as good or bad news.

Furthermore, some VSAs require a previous process of analysis, e.g. a judge's verdict or an evaluating committee's report. So, we can describe VSAs as analytical or non-analytical. The point here is not that we assume that there was a process of analysis preceding the VSA, but that the analytical VSA itself presupposes such a process (of which it is the conclusion), and this process gives the VSA and its speaker a certain authority.

\subsection{Degree of strength of the IP}

The difference between two speech acts like $X$ is beautiful and I'd say $X$ is beautiful shows that the valuative IP can be achieved with varying degrees of strength. This allows for VSAs that can be described as unqualified ( $X$ is beautiful) or hedged (I'd say $X$ is beautiful; To me, $X$ seems beautiful). The issue here is not the semantic strength or degree of the axiological value, which accounts for the difference between, e.g. good, very good, and the best, but the illocutionary strength with which it is ascribed.

Let's look at an example. In fragment (2) (Kudrow and Short 2018), the participants are discussing actress Lisa Kudrow's TV show and how another actress's representative confused it with a reality show.

(2) Lisa Kudrow: [...] I thought, 'Well, how's that possible?' [...] And why would I be on a reality show called The Comeback?

James Corden: The Comeback. Yes!

LK: I mean, that's the whole humiliating joke.

JC: Yes!

LK: Why would I...?

Martin Short: There's a chance she doesn't have the top people.

Short's is a negative VSA, but its illocutionary strength has been weakened by introducing it with There's a chance. Incidentally, the axiological value is also semantically hedged: instead of saying her people are BAD, Short ascribes them the value NOT THE BEST.

Other ways of hedging the valuative IP include adding to $m e$, as in $X$ is beautiful to me; the use of the adverb rather, as in rather ugly; expressions like for lack of a better word or if you will; intonation and paralinguistic means such as facial expression. I will however not go into details here. 


\subsection{Mode of achievement}

This answers the question, in what special way, if any, must the IP be achieved? For VSAs, this amounts to asking how must the value ascription be performed in order for it to count as a VSA of a certain kind. Some VSAs require the speaker to have a certain status (3.3.1), or the valuated object to be considered in a certain way (3.3.2), or the use of a certain kind a value scale (3.3.3), or the ascription to be performed in a certain kind of situation (3.3.4).

\subsubsection{Speaker status}

In principle, anyone can perform a VSA. However, some specific kinds require that the speaker have a certain recognized status, derived from an extra-linguistic institution. Anyone can say that someone is beautiful, or smart, or skilled, but only a presiding judge can pronounce someone guilty or innocent; only a licensed physician can pass a soldier fit or unfit for duty; only a working teacher can grade a student's work with an $\mathrm{A}$, or a B, or an F.

According to this criterion, then, VSAs can be described as status-based or non-status-based. This parallels Caballero Díaz's (2014) distinction between evaluations (Sp. evaluaciones), which are status-based and institutional, and appraisals (Sp. apreciaciones), which are neither.

There is a weaker version of this mode of achievement, namely, non-institutional status-based VSAs, a prime example of which is an expert's opinion. However, by "status-based VSAs" I will strongly mean "institutional status-based VSAs". What is discussed here holds for non-institutional status-based VSAs as well, albeit with some obvious qualifications.

Status-based VSAs pose a problem for at least one of the theoretical claims expounded in the previous section: that VSAs bring about a weak, inside-oriented truth commitment, and that they are therefore not truth-evaluable in the same way assertives are. Mainly because they involve an extra-linguistic institution, status-based VSAs create 'institutional facts', in Searle's $(1995,2010)$ sense, and they thus become truth-evaluable (there are speaker-independent ways of assessing their truth). ${ }^{8}$ The same holds for transcendent (cf. 3.5) and unimpeachable (cf. 3.6) VSAs. I do not believe this issue to be unresolvable, but a full account of such VSAs would have to make use of some larger framework, such as the one developed by Searle in his cited works. I therefore defer it.

8. I would further hypothesize that, in these cases, we are dealing with the distinction between epistemically subjective and epistemically objective (again in Searle's sense) values. 


\subsubsection{How the referent is considered}

There are several ways in which the referent can be considered for value ascription. It can be considered alone ( $X$ is smart, an absolute VSA, at least according to its linguistic expression, all VSAs being necessarily comparative), or it can be explicitly compared to other referents of the same class ( $X$ is smarter than $Y$, a relative VSA). This produces a kind of VSA that Caballero Díaz (2014) calls 'hierarchization'. So VSAs can be described as relative or absolute.

Relative VSAs come in different kinds. Consider the following example (Colbert et al. 2018). Here, TV host Stephen Colbert is telling his guest about his older siblings.

(3) Stephen Colbert: [...] My older brothers and sisters are like the funniest people in the world to me. My wife al... My wife always says, like, 'You get so quiet when you're around them.' And I'm like, 'Well, I can't be as funny as they are.' $[\ldots]$

Fragment (3) contains two kinds of relative value ascription. The first one, the funniest people in the world, is what Caballero Díaz (2014) calls a singularizing hierarchization': it ascribes an extreme, intensified value (the funniest) to an object (my older brothers and sisters), which is thereby presented as superior to all other members of its class (other people).

The second kind is illustrated by I can't be as funny as they are. This is what Caballero Díaz calls a 'comparative hierarchization', and it establishes a comparison between the valuated object (Colbert) and other objects of its class (his siblings). There are other possibilities that I forgo discussing due to space concerns.

Furthermore, the referent can be valuated directly (a smart author) or by means of a referential shift (a smart novel). Shifted value ascriptions like a smart novel or a clever remark are examples of metonymy, where the ascribed value will 'ricochet' to a referent appropriate to the scale being used, that is, with properties able to provide a focus (the author of the novel in the first case, the speaker of the remark in the second). VSAs can be shifted metaphorically as well, as in Jack is a mule, where the referent Jack is valuated directly, but the value is ascribed by means of a 'detour' to another referent ( $a$ mule). Both are made to coincide on the same value of the scale stubborn / flexible.

Shifted VSAs are interesting for two reasons. First, they suggest that at least some axiological values are subcategorized for certain ontological classes (and perhaps for finer semantic distinctions). And second, they seem to flout the felicity conditions put forward above, specifically the second one: the valuated object must have properties that can provide a focus for the values of the axiological scale. Still, these VSAs are felicitous, and quite common, moreover. Nevertheless, a full account of such cases must be deferred. 


\subsubsection{Value scales}

VSAs rely on value scales along which the valuated referent can be placed. In Section 2, we saw that the basic axiological scale is formed by the extreme general values GOOD and BAD, by their negations (NOT BAD and NOT GOOD), and by the conjunction of these two (NEITHER GOOD NOR BAD), as shown:

BAD $\leftarrow$ NOT GOOD $\leftarrow$ NEITHER GOOD NOR BAD $\rightarrow$ NOT BAD $\rightarrow$ GOOD

These values are to be thought of as stable semantic points along a continuum or, in Martin and White's terms, as "located along a continuous scale [...], with various intermediate points possible between [the] two extremes" $(2005,16)$.

A thorough study of value scales would require a paper of its own (or more), so I will not go into detail here. ${ }^{9}$ I will only offer some remarks that have typological significance.

The basic scale above is a template from which particular value scales can be built. It has certain formal properties - polarity (the extreme values are contrary poles), continuousness (infinite possible values), bi-incrementality (the values go up from the middle in both directions) - that need not be preserved. It needs not even be used in its entirety. For instance, relative VSAs like the best or the worst pick out one of the extremes and build a continuum spanning from GOoD or BAD to the highest degree possible, with any number of intermediate values. This scale is no longer bi-incremental, but simply incremental, and the extremes values (GOOD and THE BEST, and BAD and THE WORST) are no longer contrary poles.

However, for typological purposes, I will focus on two properties of axiological scales: whether they are continuous or discrete, and whether they are institutional or not.

Consider the following two examples (Mirren 2018). In the first fragment (4), actress Helen Mirren is discussing actor Liam Neeson's childhood, and in the second one (5), she is talking about being in the Winchester Mystery House.

(4) Helen Mirren: [...] in this tiny little house, you know, and his three sisters, and Liam, all six-foot-four of him, and it... it was... it was amazing, absolutely amazing. Wonderful, wonderful um... experience.

(5) HM: I felt... I felt the feeling in the house was one of... of... um... it was a nice feeling. It wasn't a nasty feeling. It wasn't an aggressive, violent, or... It was... There was a sweetness about it.

9. But see, for instance, Kennedy and McNally (2005), and Solt (2015), for studies of the semantics of natural language scales, and Martin and White (2005,135-153) for a discussion of graduation within the appraisal framework. 
All of Mirren's value ascriptions in these two fragments make use of continuous axiological scales (amazing, wonderful, nice, nasty, aggressive, violent, sweetness). This continuous character is easy to identify, since the speaker makes use of gradable valuative adjectives (except for sweetness, but we can agree that this noun corresponds to a gradable predicate, to wit, 'sweet'). However, this is not the only possibility. Consider this next fragment (6) (Jones 2018), where the speaker is discussing a recent interaction with residents of Charlottesville.

(6) Van Jones: This is their home town, and a white terrorist mob came and tore their town apart $[\ldots]$

When Jones says that the mob tore their town apart, his value ascription, too, makes use of a continuous axiological scale, even if there is no gradable adjective. Tore their town apart stands at one point of a continuum that spans from affected their town, upset their town, hurt their town, tore their town apart, all the way up to shattered or devastated their town.

But the example contains more valuative material: a white terrorist mob. Now this is a different kind of scale. Valuating a group of people as 'terrorists' does not place them along an axiological continuum, but rather includes them in a category, the limits of which are more sharply defined. One might argue over whether a given person or group of people warrants the label terrorist, but the debate cannot be settled "somewhere in between". They either do, or they do not.

This is therefore a discrete axiological scale, albeit with only two values: 'terrorists' (the negative one) and 'non-terrorists' (the positive, or non-negative, one). It is also a flat scale, since there is no measurable variation between one value and the other. The scale innocent / guilty, as used in trials, is another example of a flat discrete axiological scale, while the scale A / B / C / D, etc., used in school grading, is an example of an incremental discrete axiological scale.

This difference between continuous and discrete scales amounts to a difference between kinds of VSAs: classificatory VSAs, that make use of discrete axiological scales, and descriptive VSAs, based on continuous axiological scales. However, this distinction might need to be nuanced, in the future, to incorporate what Martin and White call 'clines of prototypicality' (2005,137-140), like a true friend or a real father.

Be that as it may, this distinction is relevant because, as psychological and psycholinguistic research has shown, ${ }^{10}$ categories license inferences, and by overtly including the valuated object in a category, rather than just describing how it appears to her, the speaker invites the hearer to reason about it in specific ways.

10. See, for instance, Yamauchi and Markman (2000), Hampton and Cannon (2004), and Coley, Shafto, Stepanova, and Baraff (2005). 
A second distinction can be drawn between institutional axiological scales (provided by and grounded in an extra-linguistic institution) and non-institutional axiological scales. Most of the values we have seen, e.g. amazing, wonderful, nice, aggressive, etc., belong to non-institutional scales. Values like innocent / guilty, on the other hand, are provided by and grounded in the institution of law and criminal justice and, as such, are linked to status-based VSAs, to situationally bounded VSAs (cf. 3.3.4), to transcendent VSAs (cf. 3.5), and to unimpeachable VSAs (cf. 3.6).

\subsubsection{Situational boundedness}

Finally, most VSAs do not depend on a specific situation in order to be successful: someone can express an opinion anywhere, at any time. Some VSAs, however, are bound to a situational context, e.g. a judge's verdict is only successful within the context of a trial. If these VSAs are additionally performed as part of a conventional sequence of speech acts (as a judge's verdict is), they can be said to have a ritualistic character.

According to this criterion, then, VSAs can be described as situationally bounded or situationally unbounded. Situationally bounded VSAs can be further described as ritual or non-ritual.

\subsection{Content conditions}

What must be said, or what cannot be said, for a VSA to be successful? According to the value scale, some contents are appropriate and others are not. For instance, there cannot be graduation of discrete values (a defendant cannot be \#slightly guilty).

Further, there can only be ambiguous and ambivalent values when the scale is polar. For instance, something that is not good, but is not bad either, can be just fine (ambiguity). Or something can be good and bad at the same time (ambivalence). On the other hand, ambiguity and ambivalence are impossible with scales that have only two discrete values, like innocent / guilty. A defendant must be valuated as either guilty or innocent; they cannot be neither, and they cannot be both.

According to this criterion, then, VSAs can be described as semantically constrained or semantically unconstrained. 


\subsection{Causal force}

What effect does a successful VSA have? All speech acts have perlocutionary effects, but I am concerned here with VSAs' conventional effects. ${ }^{11}$ Some VSAs have objective consequences; they have effects in the world, where they create new states of affairs. A layman saying That painting is beautiful does not seem to me to change anything in the world, but a jury saying We find the defendant guilty in the context of a trial does. So VSAs can be described as transcendent (with conventional consequences) or non-transcendent (without such consequences). Once again, this parallels Caballero Díaz's (2014) distinction between evaluations, which have conventional consequences, and appraisals, which do not.

Other VSAs have an effect on the discourse. Speech acts enter into causal relationships with other speech acts, specifically in the context of a dialogue (Moeschler 2004). Some VSAs elicit other speech acts on the part of the interlocutor (e.g. expressions of agreement or disagreement), whereas others seem to "go unnoticed". VSAs can therefore also be described as effective (when they have an effect on dialogical discourse, without the implication that the effect is desired) or ineffective (when they do not). Effective VSAs can be further described as polemic (when they elicit expressions of disagreement) or non-polemic (when they elicit expressions of agreement).

Consider the following exchange fragment (7) (Dafoe 2018):

(7) Stephen Colbert: I've always liked your name, "Willem Dafoe". It's a little bit different.

Willem Dafoe: Yeah.

[...]

SC: Um... But it's a lie! I just found out that your name is William Dafoe...

WD: Listen...

SC: ... and you're making the rest of us sound stupid for you.

WD: No, no, no...No, it's...

SC: Why is it "Willem"? What's wrong...? What...?

WD: It's not like that.

11. Sbisà argues that, according to Austin, all speech acts are conventional, although traditionally, authors have recognized "as conventional acts only those illocutionary acts whose performance is explicitly and rigidly regulated by extralinguistic conventions" (2014, 621). It is, however, in this narrow sense that I use conventional. 
Near the end of this exchange, Colbert performs a negative, albeit humorous VSA of Dafoe's behavior (it's a lie / you're making the rest of us sound stupid). Dafoe disagrees, which makes Colbert's a polemic VSA.

This next fragment (8) (Gaffigan 2018) illustrates ineffective and nonpolemic VSAs. At the beginning of the fragment, comedian Jim Gaffigan is talking about the Vasa Museum, in Stockholm, and then his interviewer moves on to the Grammys.

(8) Jim Gaffigan: Most countries, their largest tourist attraction is, you know, an engineering marvel, or some beautiful natural thing. In Stockholm, they're like, 'This is a boat that didn't float. This is why we make furniture.' But it is a beautiful boat!

Seth Meyers: Uh, you... Congratulations! Third Grammy nomination. Will you be going to the Grammys?

JG: I-I'm actually presenting at the Grammys, and I'm really excited. It'll be fun to watch Dave Chappelle win.

SM: Oh, yeah, that's... Dave Chappelle is nominated.

JG: I mean, Dave Chappelle, he did four comedy specials this year...!

SM: Four hours in a year.

JG: ... which is insane! I don't know if I've watched four comedy specials...

SM: Yeah. And you are prolific as well, you're not a lazy comedian, but four in a year is...

JG: That's-that's un... that's...

SM: Yeah.

JG: That's wrong.

SM: Yeah.

JG: He's making us look bad.

SM: Yeah.

In Gaffigan's first turn, his VSA But it is a beautiful boat is an example of an ineffective VSA: it does not elicit any response from Meyers, who proceeds to change the topic of the conversation. The same thing happens with It'll be fun to watch Dave Chappelle win, although this time, rather than change the topic, Meyers focuses on a presupposition contained within the VSA (that Chappelle is nominated). So although Meyers technically responds to Gaffigan's VSA, this response does not relate to the VSA itself. From there on, we find a series of non-polemic VSAs, which elicit expressions of agreement from Meyers, namely, Yeah.

This last fragment (9) from the same interview presents a different case. 
(9) JG: The award shows are great, and I know you hosted, and you did a great job, by the way.

SM: Oh, thank you, thank you very much.

Gaffigan's VSA You did a great job is effective: it elicits a directly related response from Meyers, but this is neither an expression of agreement nor of disagreement. It is an expressive act of thanking. In this case, Gaffigan utters a positive VSA, but we can imagine a scenario where the speaker negatively valuates the hearer, who in turn responds with That's really hurtful or something similar, without implying agreement or disagreement. I will call these effective VSAs, which merely elicit a (typically emotional) reaction from the hearer, prompting VSAs.

This criterion is relevant because, if value ascription is in fact "a truly interpersonal matter, in that the basic reason for advancing an opinion is to elicit a response of solidarity from the addressee" (Martin, quoted in Oteíza $(2017,457)$ ), any illocutionary account of value ascription has to encompass the possible responses that VSAs elicit in a dialogical context. It is also worth exploring because of its novelty: I have no knowledge of illocutionary forces being described according to how the corresponding speech acts function in dialogue, and applying this criterion to other illocutionary forces could prove insightful.

\subsection{Impeachability}

What can the interlocutor do about a successful VSA? This issue is related to the causal force of VSAs, specifically when they have conventional effects.

Some VSAs are impeachable, that is, the interlocutor can openly express her disagreement and is not obliged to accept it. Others, however, are unimpeachable, i.e. the speaker's authority places her VSA "out of the interlocutor's reach", as far as discrediting it goes. Acceptance of unimpeachable status-based VSAs is mandatory, although the VSA's 'life' might be temporary. By way of an example, a judge's verdict cannot be impeached, although it can be appealed. The institutional grounding of the VSA forces the interlocutor to appeal to the same institution to impugn the verdict. As long as the verdict is 'alive', as long as it is not impugned, its acceptance is mandatory. ${ }^{12}$ In an Austinian framework, this could be rephrased in terms of the effect taken by the illocutionary act. The verdict 'takes effect' by being performed, and as long as it is 'in effect', its acceptance is mandatory. ${ }^{13}$

12. This should not be taken to imply that a judge's verdict is necessarily correct: judicial mistakes are always possible. Austin's example of an umpire's decisions $(1962,43)$ is also a case of unimpeachability.

13. Austin's notion of 'taking effect' $(1962,116)$ is somewhat developed by Sbisà $(2014,620-622)$. 
The fact that some VSAs are institutionally grounded and make use of institutionalized axiological scales gives valuating subjects with the required status the power to create or destroy states of affairs in social reality. The unimpeachable character of these VSAs stems from some of their other illocutionary features, mainly their mode of achievement, and from the structure of social and institutional reality. So a pragmatic account could be brought to bear on issues like what are unimpeachable VSAs used for in society, how is their unimpeachability guaranteed and safeguarded, what mechanisms are in place (or allowed to exist) for "going against" unimpeachable VSAs, among others. So this feature of (un)impeachability directly links this account of value ascription to Searle's theory of social reality $(1995,2010)$, as it allows us to think of at least some VSAs as creating 'institutional facts', in his sense. ${ }^{14}$

This criterion could also carry over to the description of other speech acts, notably declarations and directives (e.g. as constitutive of law), but also assertives (e.g. unimpeachable assertions as constitutive of religious or ideological dogma).

\subsection{Summary: A typology of VSAs}

The criteria presented above produce a rich taxonomy of VSAs, which can be summarized as shown in Table 1.

Table 1. A typology of VSAs based on illocutionary criteria

\begin{tabular}{|c|c|c|}
\hline \multirow{2}{*}{$\begin{array}{l}\text { Criteria } \\
\text { Felicity conditions }\end{array}$} & \multicolumn{2}{|c|}{ Types of VSAs } \\
\hline & felicitous & infelicitous \\
\hline Previous process of analysis & analytical & non-analytical \\
\hline Degree of strength of the IP & unqualified & hedged \\
\hline \multicolumn{3}{|l|}{ Mode of achievement } \\
\hline Speaker status & $\begin{array}{l}\text { status-based } \\
\text { (evaluations) }\end{array}$ & $\begin{array}{l}\text { non-status-based } \\
\text { (appraisals) }\end{array}$ \\
\hline \multirow[t]{2}{*}{$\begin{array}{l}\text { How the referent is } \\
\text { considered }\end{array}$} & absolute & $\begin{array}{l}\text { relative } \\
\text { (hierarchizations) }\end{array}$ \\
\hline & direct & shifted \\
\hline \multirow[t]{2}{*}{ Value scales } & based on an institutional scale & $\begin{array}{l}\text { based on a } \\
\text { non-institutional scale }\end{array}$ \\
\hline & $\begin{array}{l}\text { classificatory } \\
\text { (discrete values) }\end{array}$ & $\begin{array}{l}\text { descriptive } \\
\text { (continuous scale) }\end{array}$ \\
\hline Situational boundedness & situationally bounded & situationally unbounded \\
\hline
\end{tabular}

14. Searle actually addresses questions very similar to these ones, specifically, how are what he calls 'status functions' created and maintained in existence (2010,11-15). 
Table 1. (continued)

\begin{tabular}{llll}
\hline \multicolumn{1}{c}{ Criteria } & \multicolumn{1}{c}{ Types of VSAs } \\
\hline \multicolumn{1}{c}{$\begin{array}{l}\text { Part of a conventional } \\
\text { sequence }\end{array}$} & ritual & non-ritual & \\
$\begin{array}{l}\text { Content conditions } \\
\text { Causal force }\end{array}$ & semantically constrained & semantically unconstrained \\
Conventional consequences & transcendent & non-transcendent & \\
Effect in dialogue & effective & & ineffective \\
\multicolumn{1}{c}{ (Dis)agreement } & polemic & non-polemic & \\
Reaction & prompting & & \\
Impeachability & impeachable & unimpeachable \\
\hline
\end{tabular}

These criteria are not to be understood as mutually exclusive, but as dimensions along which VSAs can be simultaneously described. It is likely that other criteria will be identified in the future.

\section{Conclusions: VSAs in speech act theory}

So how does this account of value ascription fit in contemporary speech act theory? In an Austinian framework, primarily valuative acts fall mainly under the class of verdictives, comprised of all acts of judgment, including value ascriptions like acquitting, convicting, grading, ranking, rating, assessing, and valuing (Austin 1962,152); and behabitives, which include such acts as deploring, complimenting, criticizing, applauding, commending, blaming, and approving (159).${ }^{15}$ Some secondarily valuative acts can be found among commissives like siding with, embracing, opposing, or favoring (157), or even expositives like objecting to, adhering to, or repudiating (161). This reveals a considerable overlap in the taxonomy, while at the same time obscuring what all these acts have in common, i.e. the ascription of an axiological value. I believe this to be undesirable.

In a Searlean framework, VSAs seem to clearly fall under expressives. However, Sections 2.2 and 2.3 showed that they differ in substantial ways. Moreover, by equating axiological values to feelings and unspecified attitudes, this appears to leave little room for status-based, transcendent, or unimpeachable VSAs (a

15. It is curious that the way in which verdictives and behabitives divide value ascriptions mirrors almost exactly the distinction between classificatory and descriptive VSAs (cf. 3.3.3): verdictives seem to make use of discrete values, whereas behabitives appear to rely on continuous scales. For now, I leave it up to the reader to ponder whether this is in fact the case, and whether it is a coincidence. 
judge's verdict would have to be considered an expressive). I believe this, too, is undesirable.

The simplest solution is to go against Searle's claim that "there are five, and only five, basic primitive forms of illocutionary act, or as I say using my technical terminology, five basic illocutionary points" $(2002,5)$, and make room for one more kind: VSAs. I hope to have shown that they form a coherent and distinctive enough group to warrant a class of their own. I have not felt the need to methodically distinguish VSAs from commissives, directives, or non-valuative declarations, as I take the differences to be self-evident.

The characterization of the valuative illocutionary force in terms of illocutionary criteria provides the basis for a rich taxonomy of VSAs, which I believe to be a substantive contribution of this paper.

I have forgone discussing the details of value scales, and of hedged and shifted VSAs. Other questions have been left open: Can VSAs function as means of achieving primary IPs? Can we draw a principled, formal distinction between the intuitively different assertoric VSAs ( $X$ is beautiful) and valuative assertives (That beautiful $X$ is mine)? How does the notion of direction of fit apply to VSAs? What are the implications of paraphrasing VSAs as ' $\mathrm{X}$ seems $\mathrm{Y}$ to Z'? Would institutional VSAs (status-based, transcendent, unimpeachable), being truth-evaluable, force us to revise some of the claims made here?

A host of other problems stem from what has been presented. Further study is needed, for example, to determine whether some kinds of VSAs prefer or demand certain kinds of scales, and to formalize the subcategorizations responsible for a referent being valuated along certain scales and not others. As for the distinction between direct and shifted VSAs, we could ask ourselves what pragmatic advantages a shifted VSA affords, in relation, for example, to Brown and Levinson's (1987) concept of 'face'. This question also applies to hedged VSAs.

Seeing this considerable diversity of VSAs, we would be justified in asking in what way do the different kinds of VSAs contribute to the image of the speaker? What does each kind of VSA say about the valuating subject? And finally, what sorts of entailments or implicatures do VSAs license? What can or can't I say after a VSA, without it affecting the coherence of my discourse? All this shows the viability and potential fruitfulness of this account of value ascription.

Near the end of How to Do Things with Words, Austin mentions the case of the word good, an archetypical valuative predicate, and philosophers' longstanding interest in it and in how we use it (for expressing approval, commending, grading, etc.). He concludes that 
we shall not get really clear about this word 'good' and what we use it to do until, ideally, we have a complete list of those illocutionary acts of which commending, grading, \&c., are isolated specimens - until we know how many such acts there are and what are their relationships and inter-connexions [sic]. (Austin 1962,162)

This research is a belated attempt to rise to the challenge.

\section{References}

Austin, J.L. 1962. How to Do Things with Words. London: Oxford University Press.

Brown, Penelope, and Stephen C. Levinson. 1987. Politeness: Some Universals in Language Use. Cambridge: Cambridge University Press. https://doi.org/10.1017/CBO9780511813085

Caballero Díaz, Leandro. 2014. Semántica y diccionario. Havana: Ciencias Sociales.

Colbert, S., J. Stewart, C. Licht, T. Purcell, M. Bennet, and B. Julien, prods. 2018. The Late Show with Stephen Colbert. New York: CBS, January 24, 2018.

Coley, John D., Patrick Shafto, Olga Stepanova, and Elizabeth Baraff. 2005. "Knowledge and Category-Based Induction." In Categorization Inside and Outside the Laboratory: Essays in Honor of Douglas L. Medin, ed. by W. Ahn, R. L. Goldstone, B. C. Love, A. B. Markman, and P. Wolff, 69-86. Washington, DC: American Psychological Association. https://doi.org/10.1037/11156-005

Dafoe, Willem. 2018. Interview by Stephen Colbert. The Late Show with Stephen Colbert, CBS, January 24, 2018.

Gaffigan, Jim. 2018. Interview by Seth Meyers. Late Night with Seth Meyers, NBC, January 24, 2018.

Galbán Pozo, Ana María. 1999. “Análisis dimensional de verbos con semántica valorativa en lengua alemana." Masters thesis, University of Havana.

Galbán Pozo, Ana María. 2003. “Aproximación al estudio de las macro-categorías semánticas modales (valoración, lealtad, certidumbre, interés, afectividad y expresividad) y su expresión a través de verbos de las lenguas española y alemana." PhD diss., University of Havana.

González de Prado Salas, Javier, and Iván Milić. 2018. "Recommending Beauty: Semantics and Pragmatics of Aesthetic Predicates." Inquiry 61 (2): 198-221. https://doi.org/10.1080/0020174X.2016.1238778

Green, Mitchell. 2017. "Speech Acts." In The Stanford Encyclopedia of Philosophy (Winter 2017 edition), ed. by Edward N. Zalta. http://plato.stanford.edu/archives/win2017/entries/speech-acts/

Greimas, Algirdas J. 1966. Sémantique Structurale. Paris: Larousse.

Hampton, James A., and Iben Cannon. 2004. "Category-based Induction: An Effect of Conclusion Typicality.” Memory \& Cognition 32 (2): 235-243. https://doi.org/10.3758/BFo3196855

Jones, Van. 2018. Interview by Seth Meyers. Late Night with Seth Meyers, NBC, January 24, 2018.

Kennedy, Christopher, and Louise McNally. 2005. "Scale Structure, Degree Modification, and the Semantics of Gradable Predicates." Language 81 (2): 345-381.

https://doi.org/10.1353/lan.2005.0071 
Kölbel, M. 2003. "Faultless Disagreement." Proceedings of the Aristotelian Society 104: 55-73. https://doi.org/10.1111/1467-9264.to1-1-00003

Kudrow, Lisa, and Martin Short. 2018. Interview by James Corden. The Late Late Show with James Corden, CBS, January 31, 2018.

Martin, James R., and Peter R. R. White. 2005. The Language of Evaluation. Appraisal in English. New York: Palgrave Macmillan. https://doi.org/10.1057/9780230511910

McGowan, Rose. 2018. Interview by Stephen Colbert. The Late Show with Stephen Colbert, CBS, January 31, 2018.

Mirren, Helen. 2018. Interview by Graham Norton. The Graham Norton Show, BBC Two, January 26, 2018.

Moeschler, Jacques. 2004. "Dialogue et Causalité: Force Causale, Actes de Langage et Enchaînement." Cahiers de Linguistique Française 26: 67-85.

Oishi, Etsuko. 2006. “Austin's Speech Act Theory and the Speech Situation.” Esercizi Filosofici 1: 1-14.

Oteíza, Teresa. 2017. “The Appraisal Framework and Discourse Analysis.” In The Routledge Handbook of Systemic Functional Linguistics, ed. by T. Bartlett, and G. O'Grady, 457-472. London: Routledge.

Sbisà, Marina. 2007. "How to Read Austin." Pragmatics 17 (3): 461-473. https://doi.org/10.1075/prag.17.3.06sbi

Sbisà, Marina. 2014. "The Austinian Conception of Illocution and its Implications for Value Judgments and Social Ontology." Etica \& Politica / Ethics \& Politics 16 (2): 619-631.

Searle, John R. 1975. “A Taxonomy of Illocutionary Acts.” In Language, Mind, and Knowledge, ed. by K. Gunderson, 344-369. Minneapolis: University of Minnesota Press.

Searle, John R. 1995. The Construction of Social Reality. New York: The Free Press.

Searle, John R. 2002. "Speech Acts, Mind, and Social Reality". In Speech Acts, Mind, and Social Reality: Discussions with John R. Searle, ed. by G. Grewendorf, and G. Meggle, 3-16. Berlin: Springer. https://doi.org/10.1007/978-94-010-0589-0_1

Searle, John R. 2010. Making the Social World: The Structure of Human Civilization. New York: Oxford University Press. https://doi.org/10.1093/acprof:osobl/9780195396171.001.0001

Searle, John R., and Daniel Vanderveken. 1985. Foundations of Illocutionary Logic. Cambridge: Cambridge University Press.

Siebel, Mark. 2002. "What Is an Illocutionary Point?” In Speech Acts, Mind, and Social Reality: Discussions with John R. Searle, ed. by G. Grewendorf, and G. Meggle, 125-139. Berlin: Springer. https://doi.org/10.1007/978-94-010-0589-0_9

Solt, Stephanie. 2015. "Measurement Scales in Natural Language." Language and Linguistics Compass 9 (1): 14-32. https://doi.org/10.1111/Inc3.12101

Ulkan, M. 1992. Zur Klassification von Sprechakten. Tübigen. https://doi.org/10.1515/9783111352619 Yamauchi, Takashi, and Arthur B. Markman. 200o. "Inference Using Categories." Journal of Experimental Psychology: Learning, Memory, and Cognition 26 (3): 776-795. 


\section{Address for correspondence}

Ernesto Wong García

School of Foreign Languages

University of Havana

19 de Mayo \#14 bt. Ayestarán and Amézaga

Havana

Cuba

ewong@flex.uh.cu

\section{Biographical notes}

Ernesto Wong García conducts research within the Semantics and Discourse Studies group, at University of Havana (Cuba), which covers areas such as semantics, pragmatics, and discourse analysis. The author has focused on the expression of speaker subjectivity in discourse, specifically valuative meaning, and the formal, semantic, and pragmatic procedures involved. 
